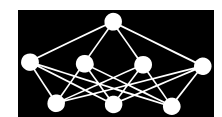

\title{
HARMONIC ESTIMATION BASED SUPPORT VECTOR MACHINE FOR TYPICAL POWER SYSTEMS
}

\author{
S. Özdemir*, M. Demirtaşџ S. Aydin
}

\begin{abstract}
The power quality in electrical energy systems is very important and harmonic is the vital criterion. Traditionally Fast Fourier Transform (FFT) and Discrete Fourier Transform (DFT) have been used for the harmonic distortion analysis and in the literature harmonic estimations have been made using different methods. As an alternative method, this paper suggested using Support Vector Machine (SVM) for harmonic estimation. The real power energy distribution system has been examined and the estimation results have been compared with measured real data. The proposed solution approach was comparatively evaluated with the ANN and LR estimation methods. Comparison results show that THD estimation values that were obtained by the SVM method are close to the THD estimation values obtained from ANN (Artificial Neural Network) and LR (Linear regression) methods. The numerical results clearly showed that the SVM method is valid for THD estimation in the power system.
\end{abstract}

Key words: power distribution system, Support Vector Machine, harmonic, power quality, THD, ANN, LR

Received: May 28, 2015

DOI: $10.14311 / \mathrm{NNW} .2016 .26 .013$

Revised and accepted: March 30, 2016

Nomenclature: $\mathrm{THD}_{I}-$ Total current harmonic distortion, $I_{L}-$ Load current, $I_{i}-i$-th input pattern, $I_{j}-j$-th input pattern, $x$ - Input space, $\mathbf{z}-$ Feature space vector, $y_{i}$ - Target value, $\xi_{i}$ - Slack variable, $b$ - Bias, $\varepsilon$ - Intensive loss function, $\mathrm{L}-$ Lagrange function, $f(I)$ - Estimation function, $\alpha_{i}, \alpha_{i}^{*}, n_{i}, n_{i}^{*}$ - Lagrange multipliers, $C$ - Constant, $w$ - Weight factor

\section{Introduction}

With the development of industry and technology, energy users now pay more attention to the quality of power. Non-linear loads, such as television, computer, air conditioning, UPS, speed control devices and welding machines, generate power

\footnotetext{
*Suat Ozdemir - Corresponding author, Celal Bayar University, Turgutlu MYO, Electrical Department, Turgutlu/Manisa, Turkey, E-mail: suat.ozdemir@cbu.edu.tr

${ }^{\dagger}$ Metin Demirtas, Balıkesir University, Engineering Faculty, Electric-Elecktronic Eng. Dept., Balıkesir, Turkey, E-mail: mdtas@balikesir.edu.tr

$¥$ Serkan Aydin, Celal Bayar University, Technology Faculty, Mechatronic Eng. Dept. Turgutlu/Manisa, Turkey, E-mail: serkan.aydin@cbu.edu.tr
} 
system harmonics. These harmonics disrupt the ideal voltage and current waveforms, and cause problems with power quality [59]. At the same time, harmonics lead to losses of transformers and power distribution systems, trenches, disruption in communication systems, and sudden trips $[55,1]$. Total Harmonic Distortion (THD) is used as an indication of current and voltage distortion values. Harmonic limitations are described in the IEEE 519 standard $[15,14]$. In addition, reference $[12,13]$ describe the harmonic distortion limit values in IEC standards.

In this study we proposed the SVM method for harmonic estimation. In the literature, harmonic estimation has been made with different methods. We applied the SVM method to a real energy distribution system for harmonic estimation. DFT and FFT are commonly used for analyzing harmonics in power systems. Equations obtained from DFT and FFT are very complex, and solving these equations can be very difficult. Applying SVM is a simple and useful method for estimations. Once the system is modeled the $\mathrm{THD}_{I}$ estimations can be easily made using SVM methodology. In this study we demonstrate that SVM methodology is applicable to harmonic estimations on power systems.

In the literature there are several methods for the harmonic identification and estimation of power systems. ANN systems have been used in both the estimation of nonlinear harmonic loads [59] and the analysis of harmonic distortion [26]. These systems also play an important role in the quick determination of harmonics [24]. Harmonics amplitude and angle estimation have been obtained using the AN estimation method [9]. In reference [33], it has been proposed for the current estimate of nonlinear loads, which contain harmonic components. Wavelet Transform (WT) and Hilbert-Huang Transform (HHT) have been applied to the harmonic estimation of the nonlinear loads $[6,10,63,61]$. The harmonic estimations were made with very high accuracy using the Adaptive Wavelet Neural Network Based method [19]. For the identification of harmonic components the fuzzy logic method has been proposed [31]. Discrete Fourier Transform (DFT) and Fast Fourier Transform (FFT) are used to identify harmonics. However, there are some disadvantages to these methods. One of them is that DFT and FFT contain a large number of calculations. On the other hand, although DFT and FFT give accurate results, they have high complexity due to equations obtained as a result of the harmonic analysis of DFT, and accordingly need more computation time [62]. Frequency amplitudes and phases of each harmonic in the power system always change, so that FFT performance fails in these conditions [22]. DFT and FFT have some shortcomings for detecting harmonics $[4,29,37]$ and they have wide applications, but they have certain limitations in harmonic analysis [6].

Power system harmonic estimation is the most important issue for power quality. A great deal of research has been carried out on this topic and with reference to [16] Seasonal Short Term Load Forecasting has been carried out using the Curve Fitting and Regression line method. [36] presents a new algorithm that uses minimum variance criterion (MVC) and a sequential method for optimal meters placement. [52] proposes a simple symmetrical interpolation FFT algorithm, where the even terms are removed from the fitting polynomial based on the triangular self-convolution windows. Many algorithms have been proposed for harmonic estimation to improve the power quality performance but till today it is still a challenge for accurate estimation. In this case [42] an adaptive filtering 
algorithm called Fast Transverse Recursive Least Square (FT-RLS) is applied for the first time for estimating harmonic parameters and [7] presents a novel method for solving the estimation of the amplitudes and phases of different harmonic components contained in a power electrical signal, based on Particle Swarm Optimizer with Natural Selection (PSONS). Harmonic estimation and compensation are important tasks for improving power quality indexes in electric systems. In [58], the feasibility of using the discrete Fourier square-wave transform (DFSWT) as a fast processing engine, with low power consumption, for online harmonic component estimation is assessed. [17] presents a fast and accurate approach for realtime estimation of moderate time-varying harmonics of voltage/current signals. The proposed method is based on estimation of signal parameters via rotational invariance technique (ESPRIT)-assisted adaptive wavelet neural network (AWNN). [18] is a technique based on an adaptive wavelet neural network that is the most suitable for dominant low-order harmonic estimation is presented. [60] focuses on the harmonic estimation procedure based on continuous wavelet transform (CWT) when the stationary signal to be analyzed is corrupted by the non-Gaussian impulsive noise. CWT of the harmonic signal and the impulsive noise are compared, and it is proved that the parameters of the complex Morlet wavelet have significant impacts on the CWT coefficients. A novel algorithm for harmonic estimation in power distribution networks is presented in [48]. This algorithm is based on an iterative observer to perform harmonic estimation in a measured signal. Harmonics degrade the power quality of Power Systems. [46] proposed to implement the HSE problem with suitable selection algorithms to intensify the performance.

The SVM method has been applied to different types of estimations in different systems [5]. For example the estimations of the road friction constants [23], the fingerprint and palm print orientation [53], the depth of shallow buried objects [41], and alumina powder flow [28] have been conducted using this method. The specific project parameters [45], density with high accuracy [20], and density function [57] can be determined using the SVM method.

The application of the SVM method can also be seen in estimations of different events such as ISP [8] and face shape [21]. Since harmonic and inter-harmonic detection are good indicators of power quality, these detections are very important in power systems and can obtained by the SVM method. This has been done [30]. The estimations of the rotor slip [64], steel consumption [32], and scattering of electromagnetic waves [35] can also be considered as another applications of the SVM method.

Although the SVM method has several applications in literature we note that it has not been considered in the estimation of the harmonics for the power distribution systems. Therefore, SVM method has been proposed in harmonic estimation of the power systems. In this study, the modeling and simulation of the power system have been done and presented in Section 2 and in Section 3, respectively.

\section{SVM - method for harmonic estimation}

A lot of researchers have paid more attention to this method than the neural network and mathematical programming community. SVM regression method is applicable to real world problems. For example, in [27], the feature selection methods 
for mass classification have been examined. In [25], the privacy violation problem has been exploited. Post process the SVM classifier to transform it to a privacypreserving classifier with the proposed approach. [56] aims to explore whether we can improve the accuracy of an SVM classifier for micro calcification (MC) detection by incorporating prior knowledge of MCs in mammograms. In [39] a novel approach has been proposed to training noise-resilient concept detectors from click through data collected by image search engines. The SVM-based models (FixedSVM, PSO-SVM, GA-SVM) together with a BP neural network are employed to forecast Chinese inflation rate [47]. In [2], decomposition methods for SVM classification functions are developed and discussed, using polynomial approximation methods. In [54], in order to overcome the deficiency of the traditional SVM, a positive mapping between price volatilities and sample periods of underlying financial time series has been assumed according to the theorems of behavioral finance. Dissolved Gas Analysis (DGA) is an established method for detecting and predicting faults contained in power transformers. Support Vector Machine (SVM) has been actively applied to classify faults using historic DGA data [38]. Biometric systems accurately recognize/authenticate an individual to access his confidential data/accounts multiple biometric traits cannot be cloned simultaneously and hence it is highly secured system. In [50] SVM based fusion of match scores for face and fingerprint biometric trait is implemented. MRI is the most important technique, in detecting the brain tumor. A new hybrid technique based on the support vector machine (SVM) and fuzzy c-means for brain tumor classification is proposed in [34]. In [11] the parameters of SVM model are pretreated through genetic algorithms to get the optimum parameter values, and these parameter values are used in the SVM model and genetic algorithm-support vector machine (GA-SVM) model is obtained, which will be used to make leakage forecasting for water supply network. We therefore use this method in order to estimate harmonics in power systems.

The regression problem has been investigated in a study carried out by S. K. Shevade et al. [40]. A good overview of the solution to this regression problem has been presented in a tutorial prepared by Smola and Schölkopf [43]. C. J. C. Burges explains in their study what SVM and Support Vector Regression (SVR) are. They differ from comparable approaches such as artificial neural networks: SVM training continuously finds a global minimum, and their simple geometric interpretation provides fertile ground for further investigation [4].

SVM are learning machines implementing the structural risk minimization inductive principle to obtain good generalization on a limited number of learning patterns. Traditional/statistical regression procedures are often stated as the processes deriving a function $f(x)$ that has the least deviation between the predicted and experimentally observed responses for all training examples. One of the main characteristics of SVR is that instead of minimizing the observed training error, SVR attempts to minimize the generalized error bound so as to achieve generalized performance. SVR is the most common application form of SVMs.

We will use $I$ and $\mathbf{z}$ to denote the input and feature space which is related to the vector of the SVM and $\mathbf{z}$ to denote the feature space vector which is related to $I$ by a transformation $\mathbf{z}=\emptyset(I)$. Let the training set $I_{i} y_{i}$ consist of $l$ data set where $I_{i}$ is the $\mathrm{i}$-th input pattern and $\mathrm{THD}_{I}$ is the corresponding target value. The 
goal of SVM regression is to estimate a function $f(I)$ that is as 'close' as possible to the target values $\mathrm{THD}_{I}$ for every $I_{i}$ and at the same time, is as 'flat' as possible for good generalization. We will refer to $\alpha_{i}$ as Lagrange multipliers. $\xi_{i}$ denotes the slack variable. $C$ is the constant. [44]:

The function $f$ is represented using a linear function as follows in Eq. (1) [43],

$$
f(I)=\left(w, I_{i}\right)+b,
$$

where $b$ denotes the bias, $w$ is the weight factor.

It is required to minimize $\|w\|^{2}$ in order to optimize the function $f(I)$. This can be performed by a convex optimization problem which can be solved by minimizing $\frac{1}{2}\|w\|^{2}$

$$
\begin{gathered}
\operatorname{minimize} \frac{1}{2}\|w\|^{2} \\
\text { s.t. }\left\{\begin{array}{l}
\operatorname{THD}_{I}-\left\langle w, I_{i}\right\rangle-b \leq \varepsilon, \\
\left\langle w, I_{i}\right\rangle+b-\mathrm{THD}_{I} \leq \varepsilon .
\end{array}\right.
\end{gathered}
$$

This inner-product kernel helps in taking the dot product of two vectors in the feature space without constructing it explicitly. For SVM regression purposes, Vapnik [49] suggested the use of $\varepsilon$ insensitive loss function where the error is not penalized as long as it is less than $\varepsilon$. It is assumed here that $\varepsilon$ is known a priori. This optimization problem is feasible. If there are slack variables $\left(\xi_{i}\right)$, the optimization expression can be written as follows:

$$
\begin{gathered}
\frac{1}{2}\|w\|^{2}+C \sum_{i=1}^{l}\left(\xi_{i}+\xi_{i}^{*}\right) \\
\text { with }\left\{\begin{array}{c}
\operatorname{THD}_{I}-\left\langle w, I_{i}\right\rangle-b \leq \varepsilon+\xi_{i}, \\
\left\langle w, I_{i}\right\rangle+b-\operatorname{THD}_{I} \leq \varepsilon+\xi_{i}^{*}, \\
\xi_{i}, \xi_{i}^{*} \geq 0 .
\end{array}\right.
\end{gathered}
$$

The intensive loss function $|\xi|_{\varepsilon}$ has been defined by

$$
|\xi|_{\varepsilon}=\left\{\begin{array}{cc}
0 & \text { if }|\xi|<\varepsilon \\
|\xi|-\varepsilon & \text { otherwise. }
\end{array}\right.
$$

For the nonlinear functions in dualization method has been described as follows:

$$
\begin{aligned}
L= & \frac{1}{2}\|w\|^{2}+C \sum_{i=1}^{l}\left(\xi_{i}+\xi_{i}^{*}\right)-\sum_{i=1}^{l} \alpha_{i}\left(\varepsilon+\xi_{i}-\operatorname{THD}_{I}+\left\langle w, I_{i}\right\rangle+b\right) \\
& -\sum_{i=1}^{l} \alpha_{i}^{*}\left(\varepsilon+\xi_{i}^{*}-\operatorname{THD}_{I}-\left\langle w, I_{i}\right\rangle-b\right)-\sum_{i=1}^{l}\left(n_{i} \xi_{i}+n_{i}^{*} \xi_{i}^{*}\right) .
\end{aligned}
$$

The primal variables $\left(w, b, \xi_{i}, \xi_{i}^{*}\right)$ have been vanished in order to obtain optimality

$$
\frac{\partial L}{\partial B}=\sum_{i=1}^{l}\left(\alpha_{i}^{*}-\alpha_{i}\right)=0,
$$




$$
\frac{\partial L}{\partial B}=w-\sum_{i=1}^{l}\left(\alpha_{i}^{*}-\alpha_{i}\right) I_{i}=0
$$

where

$$
\begin{gathered}
w=\sum_{i=1}^{l}\left(\alpha_{i}-\alpha_{i}^{*}\right) I_{i}, \\
\frac{\partial L}{\partial \xi_{i}^{*}}=C-\alpha_{i}^{*}-n_{i}^{*}=0 .
\end{gathered}
$$

From these relations, the dual optimization problem can be solved by maximizing the expression given below

$$
\left\{-\frac{1}{2} \sum_{i, j=1}^{l}\left(\alpha_{i}-\alpha_{i}^{*}\right)\left(\alpha_{j}-\alpha_{j}^{*}\right)\left\langle I, I_{j}\right\rangle-\varepsilon \sum_{i, j=1}^{l}\left(\alpha_{i}+\alpha_{i}^{*}\right) \sum_{i=1}^{l} \operatorname{THD}_{I}\left(\alpha_{i}-\alpha_{i}^{*}\right)\right.
$$

with the condition of $\sum_{i=1}^{l}\left(\alpha_{i}-\alpha_{i}^{*}\right)=0$ and $\alpha_{i}, \alpha_{i}^{*} \in[0, C]$.

Support vector function can be written in terms of expansion given as follows:

$$
f(I)=\sum_{i=1}^{l}\left(\alpha_{i}-\alpha_{i}^{*}\right)\left\langle I_{i}, I\right\rangle+b .
$$

The primal current variables $I_{i}$ can easily be determined and estimations for $\mathrm{THD}_{I}$ can be done when the current values obtained from energy system are used.

\section{Problem definition}

The harmonic for residential areas and industrial zones in Manisa have been measured and training data set have been considered. Then the dot products are computed. Kernel function has been selected. After these steps dot products and constant terms are added up. Finally the $\mathrm{THD}_{I}$ values have been estimated with SVM method. The load current $\left(I_{L}\right)$ values have been considered as input and total current harmonic distortions $\mathrm{THD}_{I}$ values have been considered as output in the SVM model.

For residential areas, one phase has been investigated so that one input and one output have been used in SVM model. For industrial zones three phases have been investigated so that three inputs and three outputs have been used in SVM model. The measured and estimated $\mathrm{THD}_{I}$ values have been compared each other. The results have been given in both numerical and graphically.

The load current $\left(I_{L}\right)$ values have been considered as input and total current harmonic distortions $\mathrm{THD}_{I}$ values have been considered as output in the SVM model. The models are shown in Fig. 1 and Fig. 2.

Fig. 2 presents the three-phase model for three methods. Inputs and Outputs are the load currents and $\mathrm{THD}_{I}$ values that measured from the system, respectively.

The algorithm is developed for SVM to estimate $\mathrm{THD}_{I}$ values. Computational process of the SVR is shown in Fig. 3. as a flowchart [49]. 
Özdemir S., Demirtaş M., Aydin S.: Harmonic estimation based...

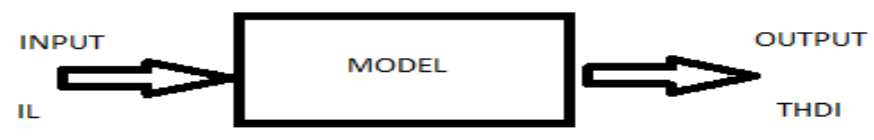

Fig. 1 The single-phase model for SVM, LR and ANN.

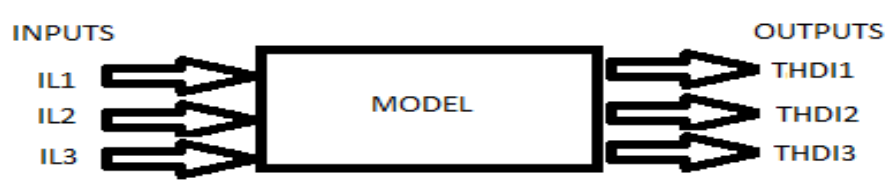

Fig. 2 The three-phase model for $S V M, L R$ and $A N N$.

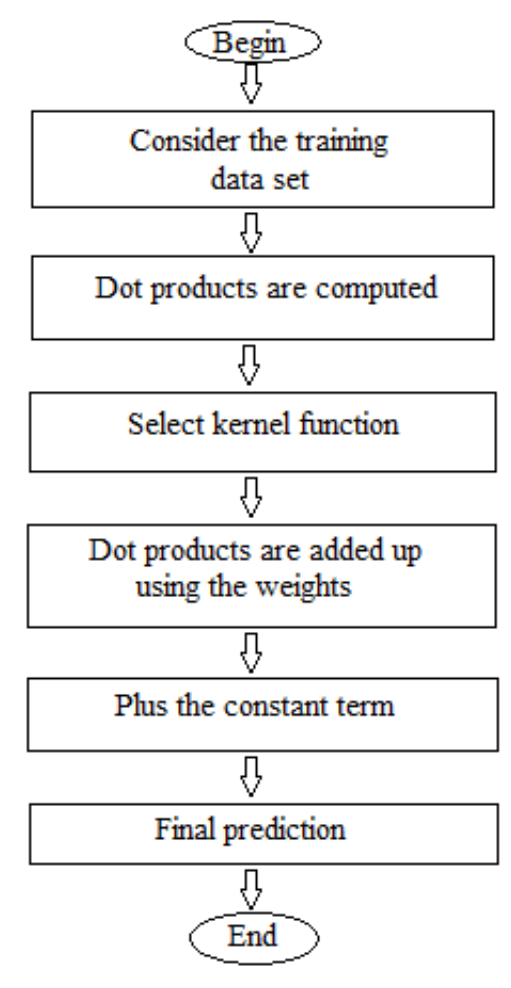

Fig. 3 Flowchart of computational process.

\section{Results and discussions}

In this study, harmonic measurements and estimations for residential areas and industrial zones in Manisa have been investigated. For this purpose, in the first step the real energy distribution system in Manisa has been modeled. The corresponding single line diagram is obtained and given in Fig. 4. As seen from this figure, transformers transform the voltage from $154 \mathrm{kV}$ to $34.5 \mathrm{kV}$. 


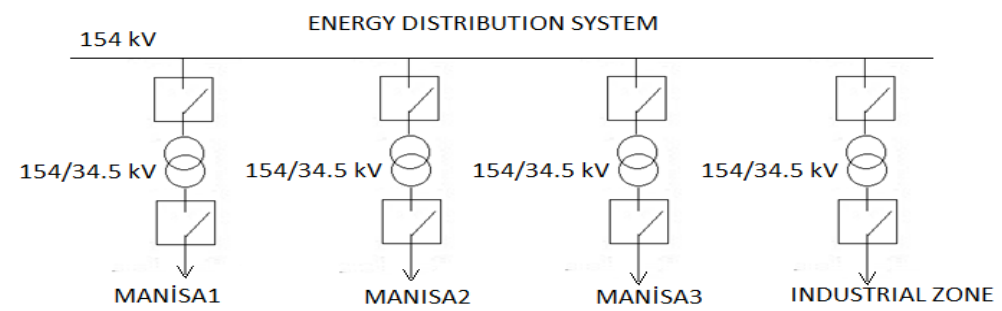

Fig. 4 Single-line diagram for the energy distribution system.

As a second step, harmonic measurements for residential areas and industrial zones have been taken from the real system. The single-line diagram of the energy distribution systems in these places has been presented in Fig. 3 and Fig. 4, respectively. $\mathrm{THD}_{I}$ measurements in single-line diagrams have been taken at the $34.5 \mathrm{kV}$. These measured $\mathrm{THD}_{I}$ values have been used by SVM for training and testing purposes.

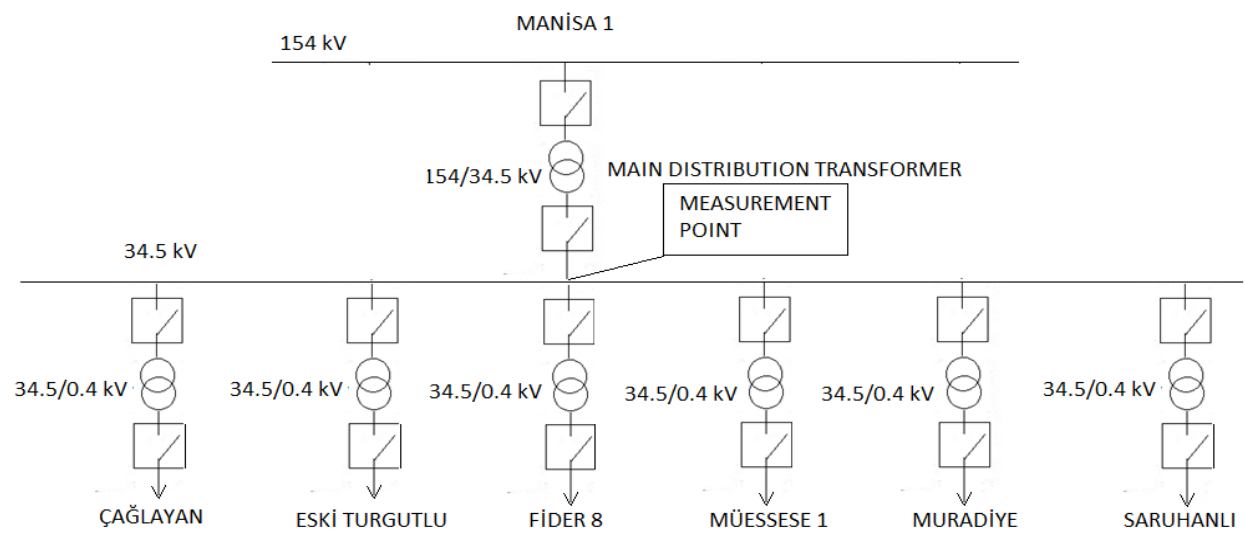

Fig. 5 Single-line diagram of the energy distribution system in residential areas.

Data set have been divided into a training set and a test. Training data is the data set that your model is derived from. Training set is implemented to build up a model. Test data is the data set that you would like to evaluate the performance of your model. The test data set have been used to validate the model.

The measuring points are shown on the Figs. 5 and 6 .

As a third step, the load current $\left(I_{L}\right)$ and $\mathrm{THD}_{I}$ measurements for residential and industrial zones are performed. The load current and $\mathrm{THD}_{I}$ are considered as input and output in the SVM model, respectively. The measurement results are depicted in Tab. I and Tab. II. Measured data have been used for training and testing the SVM method. The data in Tab. I and Tab. II are different each other. Both of the data are taken the same real system. The data used for the training the SVM is given in Tab. I. The data used for testing the accuracy of the model is presented in Tab. II. 
Özdemir S., Demirtaş M., Aydin S.: Harmonic estimation based...

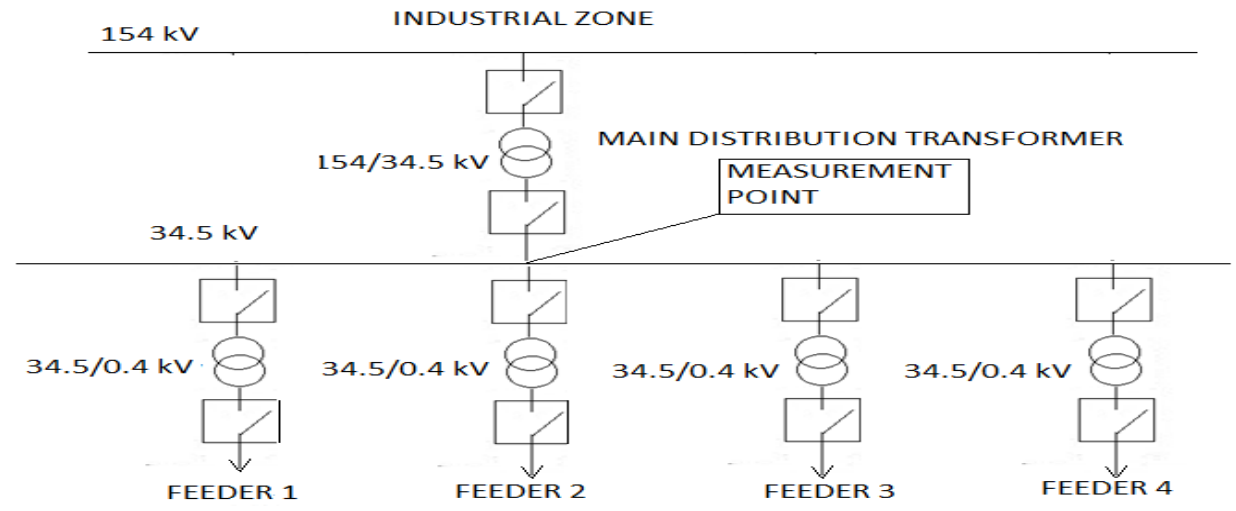

Fig. 6 Single-line diagram for the energy distribution system in industrial zone.

\begin{tabular}{lccccccccccccccc}
\hline Measurement Number & 1 & 2 & 3 & 4 & 5 & 6 & 7 & 8 & 9 & 10 & 11 & 12 & 13 & 14 & 15 \\
\hline The load current $I_{L}$ & 370 & 330 & 270 & 250 & 240 & 220 & 290 & 365 & 447 & 465 & 470 & 480 & 490 & 475 & 238 \\
Measured THD $_{I}$ & 8.4 & 8.7 & 11 & 12 & 13 & 18 & 12 & 8.8 & 7 & 6.8 & 6.6 & 6.7 & 6 & 5.8 & 14 \\
\hline
\end{tabular}

Tab. I Measured Load Current $I_{L}$ and THD ${ }_{I}$ values for training of the SVM model in residential areas.

\begin{tabular}{|c|c|c|c|c|c|c|c|c|c|}
\hline Measurement Number & 1 & 2 & 3 & 4 & 5 & 6 & 7 & 8 & 9 \\
\hline The load current $I_{L}$ & 425 & 440 & 477 & 448 & 410 & 360 & 260 & 300 & 380 \\
\hline Measured $\mathrm{THD}_{I}$ & 7 & 7.1 & 5.8 & 6.8 & 7.8 & 9 & 12 & 12 & 8.4 \\
\hline
\end{tabular}

Tab. II Measured Load Current $I_{L}$ and THD $D_{I}$ values for testing of the SVM model in residential areas.

\begin{tabular}{|c|c|c|c|c|c|c|c|c|c|}
\hline Measurement Number & 1 & 2 & 3 & 4 & 5 & 6 & 7 & 8 & 9 \\
\hline Mea & 7 & 7.1 & 5.8 & 6.8 & 7.8 & 9 & 12.2 & 11.8 & 8.4 \\
\hline Estimated $\mathrm{THD}_{I}$ & 7.63 & 7.26 & 6.33 & 7.06 & 8.01 & 9.2 & 11.76 & 10.76 & 8.76 \\
\hline Percentage error & 9 & 2.25 & 9.1 & 3.8 & 2.69 & 2.22 & 3.6 & 8.81 & 4 \\
\hline
\end{tabular}

Tab. III Percentage error, measured THD , estimated $T H D_{I}$ values for $S V M$ model.

In the forth step. the measured and estimated $\mathrm{THD}_{I}$ values and percentage error in these values for residential areas have been presented in Tab. III. As seen from Tab. III. it can be said that there is a little difference between measured and estimated values and they are very close to each other. 


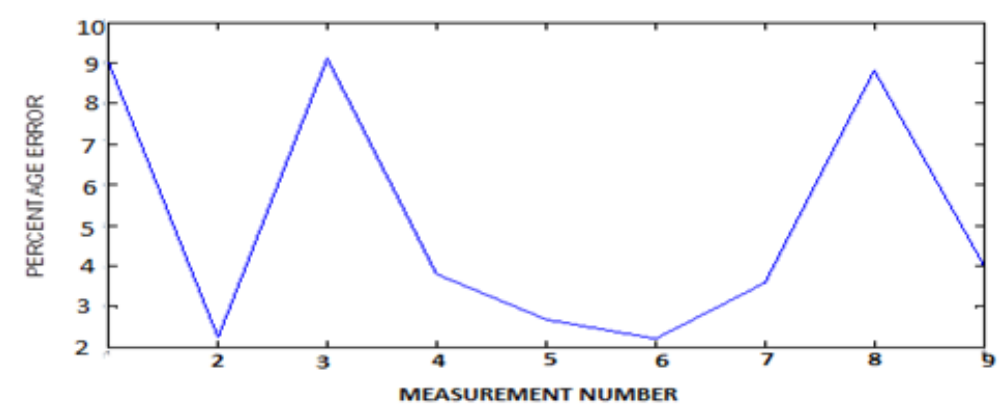

Fig. 7 The percentage error between measured $T H D_{I}$ and estimated $T H D_{I}$ values.

After this step, the percentage errors of $\mathrm{THD}_{I}$ estimations, which have been made by SVM estimation method, have been plotted in Fig. 7. The highest and lowest error is found as $9.1 \%$ and $2.2 \%$, respectively. The average error for residential areas is $5.05 \%$. This indicates that the harmonic estimation has been done with the accuracy $94.95 \%$.

The corresponding measurements have been done for industrial zones, these measurements have been taken in three phases and measurement results have been presented in Tab. IV. In this table $I_{L} 1, I_{L} 2, I_{L} 3, \mathrm{THD}_{I} 1, \mathrm{THD}_{I} 2$ and $\mathrm{THD}_{I} 3$ correspond to load current and $\mathrm{THD}_{I}$ measurement values in phase1, phase 2 and phase3. Measured data between 1-15 and 16-23 have been used to train and test the SVM model, respectively. The data used for the training the SVM is given in Tab. IV. The data used for testing the accuracy of the model is presented in Tab. V.

\begin{tabular}{|c|c|c|c|c|c|c|c|c|c|c|c|c|c|c|c|}
\hline Iea & 1 & 2 & 3 & 4 & 5 & 6 & 7 & 8 & 9 & 10 & 1 & 12 & 13 & 14 & 5 \\
\hline & & & & & & & & & & & & & & & \\
\hline & & & & & & & & & & & & & & & 2 \\
\hline & 然 & & & & & . & & & & & & . & & & 23 \\
\hline & 82 & & & 7.9 & 9 & 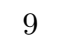 & & & .2 & 5 & 9 & 3 & 3 & .3 & 6. \\
\hline & 7.6 & & & 7.7 & 10 & & & & 7.1 & 6.4 & 5.9 & 7.3 & 5.8 & 6. & 6. \\
\hline Meas & 7.9 & 8.1 & 8.6 & 7.8 & 9.5 & 8.5 & 7.8 & 8.8 & 7.9 & 6.4 & 5.7 & 7.7 & 5.6 & 6.1 & 6.3 \\
\hline
\end{tabular}

Tab. IV Measured three-phase current $I_{L}$ and $T H D_{I}$ values for training SVM model in industrial zones.

The measured and estimated $\mathrm{THD}_{I}$ values for three phases in industrial zone and percentage error are given in Tab. VI. All $\mathrm{THD}_{I}$ values in three phases have been used in order to test the SVM method. From these values. it can be said that $\mathrm{THD}_{I}$ values estimated by SVM method for three phases are generally in good agreement with the corresponding measured ones.

The percentage errors between the measured and estimated $\mathrm{THD}_{I}$ values for three phases given in Tab. VI have been shown in Figs. 6-8. The corresponding percentage errors for $\mathrm{THD}_{I} 1$ are given in Fig. 6. As seen from Fig.8, the highest 
Özdemir S., Demirtaş M., Aydin S.: Harmonic estimation based...

\begin{tabular}{lcccccccc}
\hline Measurement Number & 16 & 17 & 18 & 19 & 20 & 21 & 22 & 23 \\
\hline The load current $I_{L} 1$ & 238 & 213 & 205 & 191 & 193 & 214 & 219 & 215 \\
The load current $I_{L} 2$ & 237 & 213 & 205 & 189 & 197 & 216 & 219 & 215 \\
The load current $I_{L} 3$ & 241 & 216 & 207 & 190 & 197 & 220 & 224 & 220 \\
Measured THD 1 & 5.3 & 7.1 & 7.6 & 8.5 & 8.1 & 8.2 & 7.4 & 8.2 \\
Measured THD $_{I} 2$ & 5.3 & 7 & 7.3 & 8.3 & 7.5 & 8.1 & 7.2 & 8 \\
Measured THD $_{I} 3$ & 5.1 & 6.8 & 7.4 & 8.1 & 7.4 & 7.8 & 7.2 & 7.9 \\
\hline
\end{tabular}

Tab. V Measured Load Current $I_{L}$ and THD I values for testing of the SVM model in industrial zone.

\begin{tabular}{lcccccccc}
\hline Measurement Number & 1 & 2 & 3 & 4 & 5 & 6 & 7 & 8 \\
\hline Measured $\mathrm{THD}_{I} 1$ & 5.3 & 7.1 & 7.6 & 8.5 & 8.1 & 8.2 & 7.4 & 8.2 \\
Estimated $\mathrm{THD}_{I} 1$ & 7.1 & 8.28 & 8.65 & 9.36 & 9.24 & 8.23 & 7.99 & 8.21 \\
Percentage error $\mathrm{THD}_{I} 1$ & 34 & 16.6 & 13.8 & 10.1 & 14.1 & 0.37 & 7.97 & 0.12 \\
Measured $T H D_{I} 2$ & 5.3 & 7 & 7.3 & 8.3 & 7.5 & 8.1 & 7.2 & 8 \\
Estimated $\mathrm{THD}_{I} 2$ & 6.74 & 8.06 & 8.49 & 9.31 & 8.91 & 7.87 & 7.74 & 7.94 \\
Percentage error $\mathrm{THD}_{I} 2$ & 27.2 & 15.1 & 16.3 & 12.2 & 18.8 & 2.84 & 7.5 & 0.75 \\
Measured THD $\mathrm{TH}_{I} 3$ & 5.1 & 6.8 & 7.4 & 8.1 & 7.4 & 7.8 & 7.2 & 7.9 \\
Estimated THD 3 & 6.92 & 7.86 & 8.22 & 8.85 & 8.6 & 7.72 & 7.57 & 7.71 \\
Percentage error $\mathrm{THD}_{I} 3$ & 35.7 & 15.6 & 11.1 & 9.26 & 16.2 & 1.026 & 5.14 & 2.405 \\
\hline
\end{tabular}

Tab. VI Percentage error measured and estimated $T H D_{I}$, estimated $T H D_{I}$ values for industrial zone.

and the lowest estimation errors are $34 \%$ and $0.12 \%$. The average of the estimation error has been calculated as $12.13 \%$. Accordingly, it can be said that the accuracy in harmonic estimations for $\mathrm{THD}_{I} 1$ is $87.87 \%$.

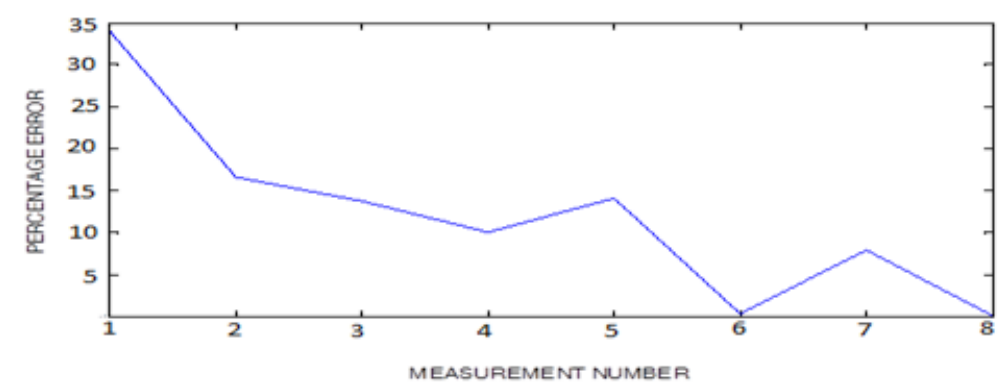

Fig. 8 The percentage error between measured and estimated $T H D_{I} 1$ values in phase1. 
In Fig. 9, the percentage error in $\mathrm{THD}_{I} 2$ values has been plotted against measurement number. Calculation results give the average error for $\mathrm{THD}_{I} 2$ as $12.5 \%$, and this corresponds to the accuracy of $87.5 \%$ in harmonic estimations for $\mathrm{THD}_{I} 2$. Moreover, the highest percentage error value in test data decreases while the lowest error value is increasing as compared to the corresponding percentage errors in $\mathrm{THD}_{I} 1$.

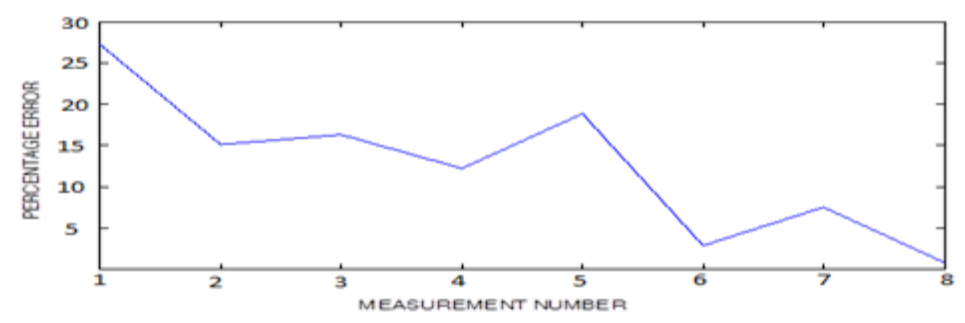

Fig. 9 The percentage error between measured $T H D_{I} 2$ and estimated $T H D_{I} 2$ values.

The corresponding percentage errors for $\mathrm{THD}_{I} 3$ have been calculated and the calculation results have been given in Fig. 10. In case of phase 3, the SVM estimation error in test data is larger than the cases of phase1 and phase2 (35.7\%). The lowest value for SVM estimation error continues to increase and it is $1.02 \%$. The average estimation error has been found as $12.05 \%$. This value is equivalent to an accuracy of $87.97 \%$ in harmonic estimations. The calculation results for percentage errors in $\mathrm{THD}_{I}$ value have shown that harmonic estimations for residential areas and industrial zones have high accuracy.

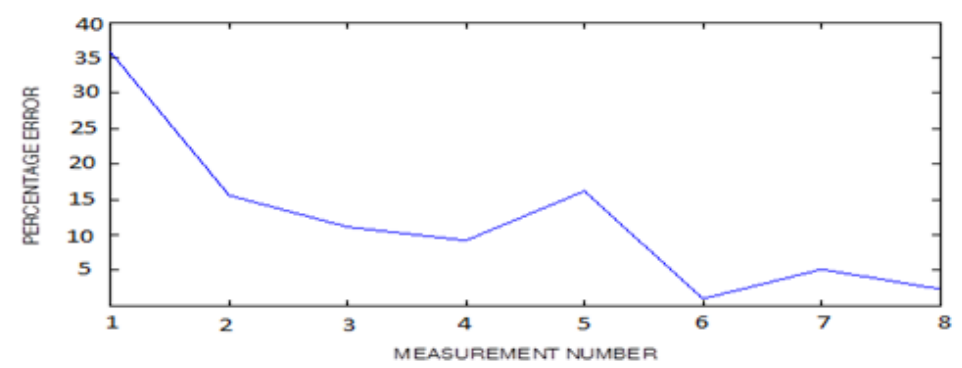

Fig. 10 The Percentage error between measured $T H D_{I} 3$ and estimated $T H D_{I} 3$ values.

Finally, the comparisons of the measured and estimated $\mathrm{THD}_{I}$ values for residential areas and industrial zones have been done in Figs. 9-12. The comparisons for industrial zones have been given separately in each phase. As seen from Fig. 11, the differences between the measured and estimated $\mathrm{THD}_{I}$ values are very small, but we see that this difference increases in the seventh and eighth measurements. However, it can be said that the measured and estimated $\mathrm{THD}_{I}$ values have become very close to each other in the sixth measurements. 
Özdemir S., Demirtaş M., Aydin S.: Harmonic estimation based...

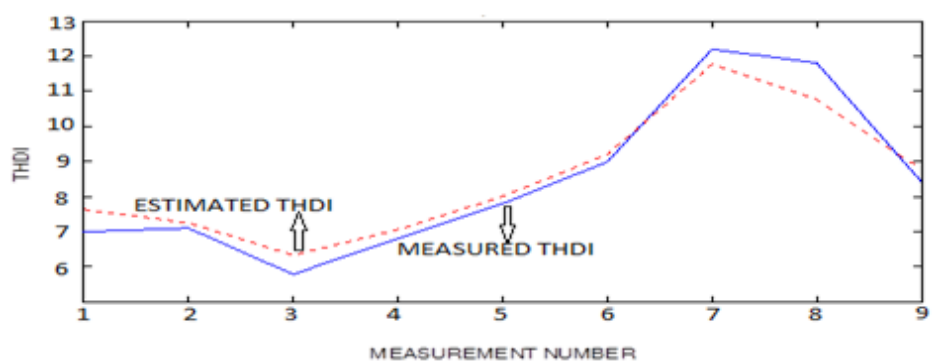

Fig. 11 The measured $T H D_{I}$ and estimated $T H D_{I}$ values for residential areas.

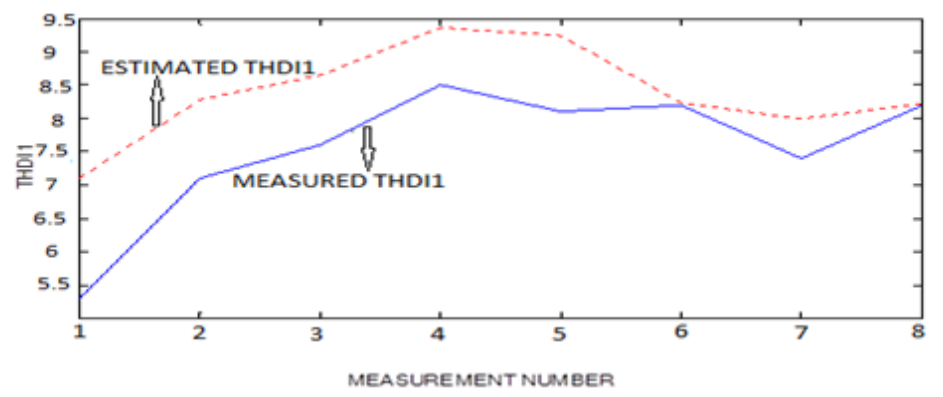

Fig. 12 The measured $T H D_{I} 1$ and estimated $T H D_{I} 1$ values for industrial zones.

In Fig. 12, the corresponding comparisons for $\mathrm{THD}_{I} 1$ in industrial zones have been depicted. The results show that there is a large difference between the measured and estimated $\mathrm{THD}_{I} 1$ values up to the sixth measurement. In the sixth and eighth measurements, $\mathrm{THD}_{I} 1$ values are almost same. In the seventh measurement, the difference is not so much large.

The behaviors of the $\mathrm{THD}_{I} 2$ and $\mathrm{THD}_{I} 3$ values are given in Fig. 13 and Fig. 14. Their behaviors are similar to $\mathrm{THD}_{I} 1$ values shown in Fig. 9. The differences between the measured and estimated $\mathrm{THD}_{I}$ values are also seen more pronounced in these figures.

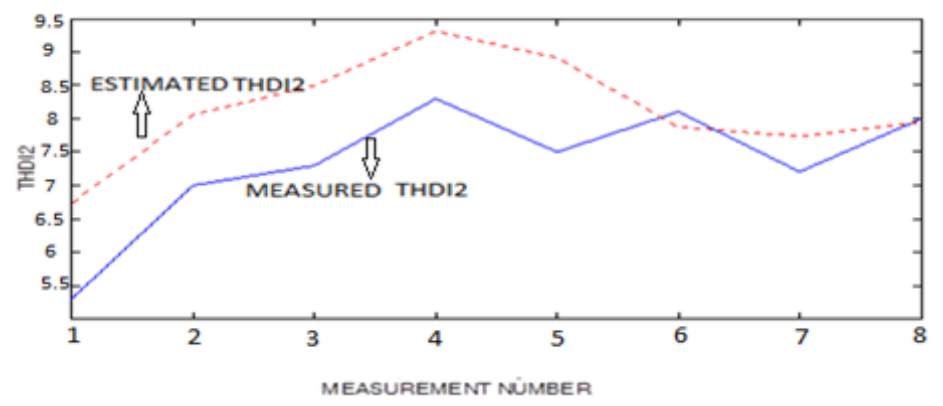

Fig. 13 The measured $T H D_{I} 2$ and estimated $T H D_{I} 2$ values for industrial zones. 


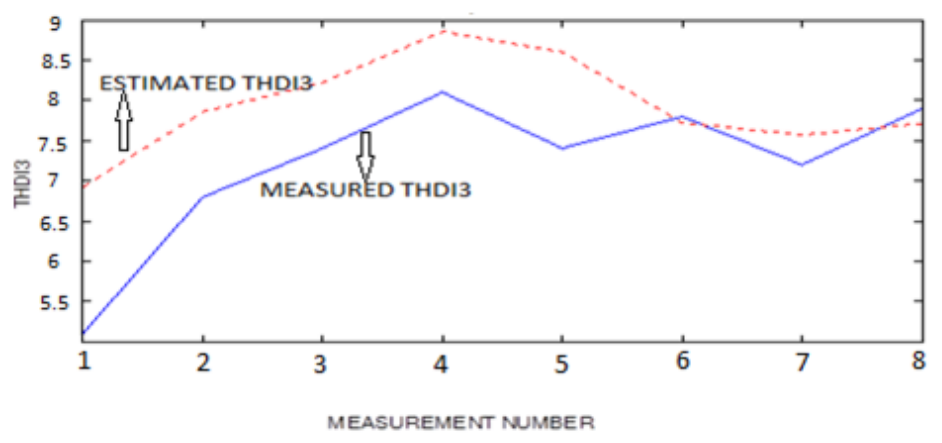

Fig. 14 The measured $T H D_{I} 3$ and estimated $T H D_{I} 3$ values for industrial zones.

\section{Discussion on the validity of the proposed approach}

ANN method has been applied to check the validity of the SVM estimation method. The single-phase systems are generally used for residential areas. The three-phase systems are used for industrial zones. Therefore, the estimations for $\mathrm{THD}_{I}$ are made for the two systems. The results have been given in following tables. The estimated values of $\mathrm{THD}_{I}$ for the single-phase obtained from the ANN model is given in Tab. VII.

\begin{tabular}{lccccccccc}
\hline Measurement Number & 1 & 2 & 3 & 4 & 5 & 6 & 7 & 8 & 9 \\
\hline Measured THD & 7 & 7.1 & 5.8 & 6.8 & 7.8 & 9 & 12.2 & 11.8 & 8.4 \\
Estimated ANN THD & 7.01 & 6.99 & 5.53 & 6.99 & 8.08 & 8.2 & 11.44 & 11.42 & 7.7 \\
\hline
\end{tabular}

Tab. VII Estimated $T H D_{I}$ values for the single-phase obtained from the ANN model.

The estimated values of $\mathrm{THD}_{I}$ for the three-phases obtained from the ANN model is presented in Tab. VIII.

\begin{tabular}{|c|c|c|c|c|c|c|c|c|}
\hline Measurement Number & 1 & 2 & 3 & 4 & 5 & 6 & 7 & 8 \\
\hline Measured $\mathrm{THD}_{I} 1$ & 5.3 & 7.1 & 7.6 & 8.5 & 8.1 & 8.2 & 7.4 & 8.2 \\
\hline Estimated ANN THD $_{I} 1$ & 5.3 & 7.4 & 1.6 & 4.9 & 1.6 & 3.5 & 9.8 & 6.6 \\
\hline Measured $\mathrm{THD}_{I} 2$ & 5.3 & 7 & 7.3 & 8.3 & 7.5 & 8.1 & 7.2 & 8 \\
\hline Estimated ANN $\mathrm{THD}_{I} 2$ & 5.3 & 7.3 & 8.2 & 8.2 & 8.7 & 7.9 & 7.9 & 7.5 \\
\hline Measured $\mathrm{THD}_{I} 3$ & 5.1 & 6.8 & 7.4 & 8.1 & 7.4 & 7.8 & 7.2 & 7.9 \\
\hline Estimated ANN $\mathrm{THD}_{I} 3$ & 5.3 & 7.1 & 7.7 & 7.6 & 7.7 & 7.8 & 7.5 & 8.3 \\
\hline
\end{tabular}

Tab. VIII Estimated values for the three-phase system obtained from the ANN model. 
Özdemir S., Demirtaş M., Aydin S.: Harmonic estimation based...

Additionally LR method has been applied to check the validity of the SVM estimation method. The results have been given in following tables. The estimated values of $\mathrm{THD}_{I}$ for the industrial zone obtained from the ANN model is given in Tab. IX.

\begin{tabular}{|c|c|c|c|c|c|c|c|c|c|}
\hline Measurement Number & 1 & 2 & 3 & 4 & 5 & 6 & 7 & 8 & 9 \\
\hline Measured $\mathrm{THD}_{I}$ & 7 & 7.1 & 5.8 & 6.8 & 7.8 & 9 & 12.2 & 11.8 & 8.4 \\
\hline Estimated LR THD ${ }_{I}$ & 7.53 & 7.14 & 6.2 & 6.94 & 7.91 & 9.1 & 11.7 & 10.7 & 8.68 \\
\hline
\end{tabular}

Tab. IX Estimated $T H D_{I}$ values for the single-phase obtained from the LR model.

The estimated values of $\mathrm{THD}_{I}$ for the three-phases obtained from the ANN model is presented in Tab. X.

\begin{tabular}{|c|c|c|c|c|c|c|c|c|}
\hline Measurement Number & 1 & 2 & 3 & 4 & 5 & 6 & 7 & 8 \\
\hline Measured $\mathrm{THD}_{I} 1$ & 5.3 & 7.1 & 7.6 & 8.5 & 8.1 & 8.2 & 7.4 & 8.2 \\
\hline Estimated LR THD ${ }_{I} 1$ & 6.89 & 8.2 & 8.6 & 9.4 & 9.27 & 8.14 & 7.88 & 8.1 \\
\hline Measured $\mathrm{THD}_{I} 2$ & 5.3 & 7 & 7.3 & 8.3 & 7.5 & 8.1 & 7.2 & 8 \\
\hline Estimated LR $\mathrm{THD}_{I} 2$ & 6.8 & 8.1 & 8.6 & 9.4 & 9.07 & 7.99 & 7.8 & 8.06 \\
\hline Measured $\mathrm{THD}_{I} 3$ & 5.1 & 6.8 & 7.4 & 8.1 & 7.4 & 7.8 & 7.2 & 7.9 \\
\hline Estimated LR $\mathrm{THD}_{I} 3$ & 6.72 & 7.85 & 8.3 & 9.06 & 8.7 & 7.6 & 7.5 & 7.6 \\
\hline
\end{tabular}

Tab. X Estimated values for the three-phase system obtained from the LR model.

The proposed solution approach comparatively evaluated with the ANN and LR estimation methods. Comparison results show that, $\mathrm{THD}_{I}$ estimation values that obtained by SVM method are close to $\mathrm{THD}_{I}$ estimation values obtained ANN and LR methods. Numerical results clearly show that the SVM method is valid for $\mathrm{THD}_{I}$ estimation in power system.

Fig. 15 illustrates the information about the measured $\mathrm{THD}_{I}$ and estimated $\mathrm{THD}_{I}$ values for SVM, ANN and LR methods. As seen from the figure, estimated $\mathrm{THD}_{I}$ values with SVM, ANN and LR methods are very close to each other.

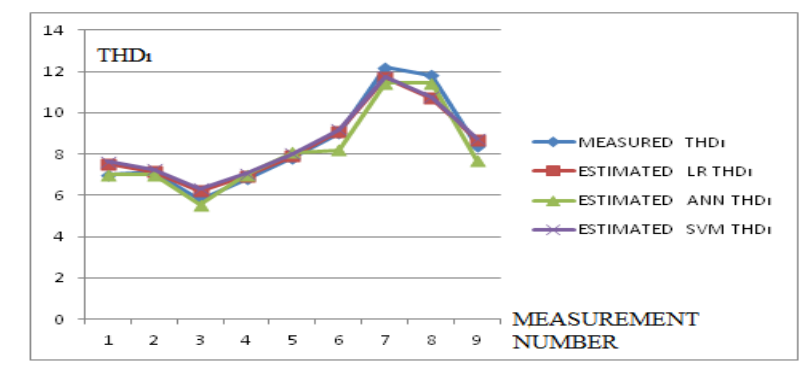

Fig. 15 The measured $T H D_{I}$ and estimated $T H D_{I}$ values for $S V M, A N N$ and $L R$ methods. 


\section{Neural Network World 3/2016, 233-252}

\section{Conclusions}

The applicability of the SVM method to harmonic estimations in energy distribution systems has been studied. For this purpose, the $\mathrm{THD}_{I}$ values have been measured and estimated by using the SVM method for residential areas and the industrial zones. The following conclusions can be drawn from the results obtained.

- Harmonic estimations in residential areas and the industrial zones have been done with high accuracy by the SVM method. This shows that this method has a good predictive power.

- On the other hand, it has been seen that the measured and estimated THD $I$ values for residential areas are very close to each other.

- From all comparisons of $\mathrm{THD}_{I}$ values for industrial zones, it has been observed that differences between the measured and estimated $\mathrm{THD}_{I}$ values occur up to sixth measurements while these values become very close to each other in the sixth and eighth measurements.

- ANN and LR methods have been applied to same testing measurements for comparing the harmonic estimations. Numerical results show that SVM based estimation method is valid for harmonic estimations in power system.

\section{References}

[1] ARRilliaga J., WATSON N.R. Power System Harmonics. John Wiley \& Sons, 2003.

[2] BAJAJ N., CHIU C.-T.G., ALLEBACH J.P. Reduction of memory footprint and computation time for embedded Support Vector Machine (SVM) by kernel expansion and consolidation. In: Proceedings of the 2014 IEEE International Workshop on Machine Learning for Signal Processing (MLSP), Reims, France. IEEE, 2014, pp. 1-6, doi: 10.1109/mlsp. 2014. 6958875.

[3] BARROS J., DIEGO R.L. Analysis of harmonics in power systems using the wavelet-packet transform, IEEE Transactions on instrumentation and Measurement. 2008, 57(1), pp. 63-69, doi: 10.1109/tim.2007.910101.

[4] BRIGHAM O. The Fast Fourier Transform. New Jersey, USA: Prentice-Hall Inc., 1974, pp. 140-146.

[5] BURGES C.J.C. A tutorial on support vector machines for pattern recognition. Data Mining Knowledge Discovery. 1998, 3(2), pp. 121-167, doi: 10.1023/A:1009715923555.

[6] CHAN Y., LAVOIE J., PLANT J. A parameter estimation approach to estimation of frequencies of sinusoids. IEEE Transactions Acoustic Speech Signal Processing. 1981, 29(2), pp. 214-219, doi: 10.1109/tassp.1981.1163543.

[7] CHEN Y., LI M.S. A harmonic parameter estimation method based on Particle Swarm Optimizer with Natural Selection. In: Proceedings of the Information and Communication Technology Research (ICTRC), Abu Dhabi, UE. IEEE, 2015, pp. 206-209, doi: 10.1109/ ictrc. 2015.7156458.

[8] CHENG X., LUO J., SHEN Z., ZHU C., ZHANG X., XIA L. Estimation of Impervious Surface Based on Integrated Analysis of Classification and Regression by using SVM. In: Proceedings of the Geoscience and Remote Sensing Symposium (IGARSS), Vancouver, BC, Canada. IEEE, 2011, pp. 2809-2812, doi: 10.1109/igarss.2011.6049864.

[9] EL-AMIN I., ARAFAH I. Artificial Neural Network for Power System Harmonic Estimation. In: Proceedings of the Harmonics and Quality of Power, Athens, Greece. IEEE, 1998, pp. 999-1009, doi: 10.1109/ichqp.1998.760178. 
Özdemir S., Demirtaş M., Aydin S.: Harmonic estimation based...

[10] EREN L., UNAL M., DEVANEY M.J. Harmonic analysis via wavelet packet decomposition using special elliptic half-band filters. IEEE Transactions on Instrumentation and Measurement. 2007, 56(6), pp. 2289-2293, doi: 10.1109/tim.2007.908244.

[11] GAO X.M., YANG S.F., HU Y. Leakage forecasting for water supply network based on GASVM model. In: Proceedings of the Piezoelectricity, Acoustic Waves and Device Applications (SPAWDA), Xiamen, China. IEEE, 2010, pp. 206-209, doi: 10.1109/spawda.2010.5744304.

[12] IEC, "Limitation of emission of harmonic currents in low-voltage power supply systems for equipment with rated current less than 16A," Standard IEC 61000-3-2, 2000.

[13] IEC, "Limitation of emission of harmonic currents in low-voltage power supply systems for equipment with rated current greater than 16A," Standard IEC 61000-3-4, 1998.

[14] IEEE, "IEEE recommended practices and requirements for harmonic control in electrical power systems," IEEE Standard 519-1992, 1992.

[15] IEEE, "IEEE Guide for Harmonic Control and Reactive Compensation of Static Power Converters" IEEE Standard 519-1981, 1981.

[16] JAIN M.B., NIGAM M.K., TIWARI P.C. Curve Fitting and Regression line method Based Seasonal Short Term Load Forecasting. In: Proceedings of the 2012 world congress on Information and communication technologies (WICT), Trivandrum, India. IEEE, 2012, pp. 332-337, doi: 10.1109/wict.2012.6409098.

[17] JAIN S.K., SINGH S.N. Fast Harmonic Estimation of Stationary and Time-Varying Signals Using EA-AWNN. IEEE Transactions on Instrumentation and Measurement. 2013, 62(2), pp. 335-343, doi: 10.1109/tim.2012.2217637.

[18] JAIN S.K., SINGH S.N. Low-Order Dominant Harmonic Estimation Using Adaptive Wavelet Neural Network. IEEE Transactions on Industrial Electronics. 2014, 61(1), pp. 428-435, doi: 10.1109/tie.2013.2242414.

[19] JAIN S.K., SAXENA D., SINGH S.N. Adaptive Wavelet Neural Network Based Harmonic Estimation Single Phase Systems. In: Proceedings of the Utility Exhibition on Power and Energy Systems, Pattaya, Thailand. IEEE, 2012, pp. 1-7, doi: 10.1109/icuepes.2011.6497764.

[20] JORDAAN E. M., NISCHENKO I., Data Analysis and Confidence based on SVM Density Estimation. In: Proceedings of the International Joint Conference on Neural Network Proceedings, Vancouver, BC, Canada. IEEE, 2006, pp. 1818-1824, doi: 10.1109/ijcnn.2006. 246900 .

[21] KIM Y., LI H. Face Pose Estimation based on EHMM and SVM. Computer Science and Service System (CSSS), Nanjing, China. IEEE, 2011, pp. 408-411, doi: 10.1109/csss. 2011. 5974897.

[22] LACHMAN T., MEMON A.P., MOHAMAD T.R., MEMON Z.A. Detection of Power Quality Disturbance Using Wavelet Transform Technique. Int. Journal for the Advancement of Science and Arts. 2010, 1(1), pp. 1-13.

[23] LI S., PEI X., MA Y., TAO L. A New Road Friction Coefficient Estimation Method Based on SVM. In: Proceedings of the International Conference on Mechatronics and Automation, Chengdu, China. IEEE, 2012, pp. 1910-1914, doi: 10.1109/icma.2012.6285113.

[24] LIN H.C. Intelligent neural network-based fast power system harmonic detection. IEEE Transactions on Industrial Electronics. 2007, 54(1), pp. 43-52, doi: 10.1109/tie.2006. 888685.

[25] LIN K.P., CHEN M.S. On the Design and Analysis of the Privacy-Preserving SVM Classifier. IEEE Transactions on Knowledge and Data Engineering. 2011, 23(11), pp. 1704-1717, doi: $10.1109 /$ tkde.2010.193.

[26] LIU Q.J., QIN S.S. A DFP - Neural Network Algorithm for Analysis of Power System Harmonics. In: Proceedings of the Power and Energy Engineering Conference (APPEEC), Chengdu, China. IEEE, 2010, pp. 1-4, doi: 10.1109/appeec.2010.5448477.

[27] LIU X., TANG J. Mass Classification in Mammograms Using Selected Geometry and Texture Features, and a New SVM-Based Feature Selection Method. IEEE Systems Journal. 2014, 8(3), pp. 910-920, doi: 10.1109/jsyst.2013.2286539. 


\section{Neural Network World 3/2016, 233-252}

[28] LU C., LI W., LIU W. Application of Soft Sensor based on LS-SVM on Estimation of Alumina Powder Flow. Measuring Technology and Mechatronics Automation, Zhangjiajie, Hunan, China. IEEE, 2009, pp. 281-284, doi: 10.1109/icmtma.2009.236.

[29] LYNN P.A., FUERST W. Introductory Digital Signal Processing with Computer Applications. John Wiley \& Sons company, 1994.

[30] MA L., LIU K., LI L. Harmonic and Inter-harmonic Detecting Based on Support Vector Machine. In: Proceedings of the IEEE/PES Transmission 85 Distribution Conference 85 Exposition: Asia and Pacific, Dalian, China. IEEE, 2005, pp. 1-4, doi: 10.1109/tdc. 2005. 1546850.

[31] MOHSEni M., ZAMANI M.A., JOORABIAN M. Harmonic Components Identification through the Adaline with Fuzzy Learning Parameter. In: Proceedings of the 33rd Annual Conference of the IEEE Industrial Electronics Society (IECON 2007), Taipei, Taiwan. IEEE, 2007, pp. 2515-2520, doi: 10.1109/iecon.2007.4460109.

[32] NI J. Material Consumption Estimation of High-rise Buildings Based on SVM. In: Proceedings of the 2013 5th International Conference on Intelligent Human-Machine Systems and Cybernetics (IHMSC), Hangzhou, China. IEEE, 2013, pp. 112-116, doi: 10.1109/ihmsc. 2013.34.

[33] OLESKOvíz M., LIMA A.A.M., BİASOTTO E., COURY D.V. Estimation of Harmonic Currents Injected by Nonlinear Loads for a Distorted Power Supply Scenario Using Artificial Neural Networks. In: Proceedings of the 2012 IEEE 15th International Conference on Harmonics and Quality of Power (ICHQP), Hong Kong. IEEE, 2012, pp. 457-462, doi: 10.1109/ichqp.2012.6381192.

[34] PARVEEN, SINGH A. Detection of brain tumor in MRI images, using combination of fuzzy c-means and SVM. In: Proceedings of the 2015 2nd International Conference on Signal Processing and Integrated Networks (SPIN), Noida, India. IEEE, 2015, pp. 98-102, doi: 10. 1109/spin.2015.7095308.

[35] PASTORINO M., RANDAZZO A. The SVM-Based Smart Antenna for Estimation of the Directions of Arrival of Electromagnetic Waves. IEEE Transactions on Instrumentation and Measurement. 2006, 55(6), pp. 1918-1925, doi: 10.1109/tim.2006.884295.

[36] RAD M.S., MOKHTARI H., KARIMI H. A new algorithm for optimal measurement placement, observability analysis and Harmonic State Estimation in power systems. In: Proceedings of the 2013 4th Conference on Power Electronics, Drive Systems and Technologies (PEDSTC), Tehran, Iran. IEEE, 2013, pp. 518-523, doi: 10.1109/pedstc.2013.6506762.

[37] RAMIREZ R.W. The FFT-Fundamental and Concepts, Prentice-Hall,1985

[38] SAHRI Z., YUSOF R. Fault diagnosis of power transformer using optimally selected DGA features and SVM. In: Proceedings of the 2015 10th Asian Control Conference (ASCC), Kota Kinabalu, Malaysia. IEEE, 2015, pp. 1-5, doi: 10.1109/ascc.2015.7360340.

[39] SARAFIS I., DIOU C., TSIKRIKA T., DELOPOULOS A. Weighted SVM from click through data for image retrieval. In: Proceedings of the 2014 IEEE International Conference on Image Processing (ICIP), Paris, France. IEEE, 2014, pp. 3013-3017, doi: 10.1109/icip. 2014.7025609.

[40] SHEVADE S.K., KEERTHI S.S., BHATTACHARYYA C., MURTHY K.R.K. Improvements to the SMO Algorithm for SVM Regression. IEEE Transactions on Neural Networks. 2000, 11(5), pp. 1188-1193, doi: 10.1109/72.870050.

[41] SINGH D. An Efficient Electromagnetic Approach to Train the SVM for Depth Estimation of Shallow Buried Objects with Microwave Remote Sensing Data. In: 2007 IEEE International Geoscience and Remote Sensing Symposium, Barcelona, Spain. IEEE, 2007, pp. 4961-4964, doi: 10.1109/igarss. 2007.4423975.

[42] SINGH S.K., NATH A., CHAKRABORTY R., KALITA J. Fast transverse-RLS algorithm based power system harmonic estimation. In: Proceedings of the 2014 International Conference on Information Communication and Embedded Systems (ICICES), Chennai, India. IEEE, 2014, pp. 1-5, doi: 10.1109/icices.2014.7034148.

[43] SMOLA A.J., SCHOLKOPF B. Learning with Kernels. MIT Press, 2002. 
Özdemir S., Demirtaş M., Aydin S.: Harmonic estimation based...

[44] SMOLA A.J., SCHOLKOPF B. A tutorial on support vector regression. Statistics and Computing. 2004, 14(3), pp. 199-222.

[45] ŠTOLFA J., KOBĚRSKÝ O., KRÖMER P., ŠTOLFA S., KOPKA M., SNÁŠEL V. Comparison of Fuzzy Rules and SVM Approach to the Value Estimation of the Use Case Parameters. In: Proceedings of the 2013 Joint IFSA World Congress and NAFIPS Annual Meeting (IFSA/NAFIPS), Edmonton, AB, Canada. IEEE, 2013, pp. 789-794, doi: 10.1109/ifsa-nafips.2013.6608501.

[46] SUPRIYA P., NAMBIAR T.N.P. Harmonic state estimation in a distribution generation system environment. In: Proceedings of the 2015 Global Conference on Communication Technologies (GCCT), Thuckalay, India. IEEE, 2015, pp. 121-124, doi: 10.1109/GCCT. 2015. 7342636.

[47] TANG Y., ZHOU J. The performance of PSO-SVM in inflation forecasting. In: Proceedings of the 2015 12th International Conference on Service Systems and Service Management (ICSSSM), Guangzhou, China. IEEE, 2015, pp. 1-4, doi: 10.1109/icsssm.2015.7170251.

[48] UJILE A., DING Z. An iterative observer for harmonic estimation in power distribution networks. In: Proceedings of the 2014 IEEE PES TESD Conference and Exposition, Chicago, IL, USA. 2014, pp. 1-5, doi10.1109/tdc.2014.6863164.

[49] VAPNIK V. The Nature of Statistical Learning Theory. New York: Springer-Verlag, 1995.

[50] VORA A., PAUNWALA C.N., PAUNWALA M. Statistical analysis of various kernel parameters on SVM based multimodal fusion. In: Proceedings of the 2014 Annual IEEE India Conference, Pune, India. IEEE, 2014, pp. 1-5, doi: 10.1109/indicon.2014.7030414.

[51] WAGNER V.E., BALDA J.C., GRIFFITH D.C., McEACHERN A. Effects of harmonics on equipment. IEEE Transactions on Power Delivery. 1993, 8(2), pp. 672-680, doi: 10.1109/ 61.216874

[52] WEN H., ZHANG J., MENG Z., GUO S. Harmonic Estimation Using Symmetrical Interpolation FFT Based On Triangular Self-Convolution Window. IEEE Transactions on Industrial

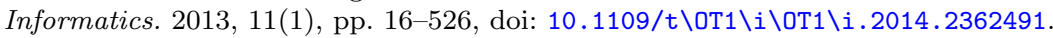

[53] WU Y., ZHAO T., WANG S., YONG A., GUO T. ASVM-based Method for the Estimation of Fingerprint and Palm print Orientation. In: Proceedings of the 2013 4th International Conference on Intelligent Control and Information Processing (ICICIP), Beijing, China. IEEE, 2013, pp. 343-348, doi: 10.1109/icicip.2013.6568095.

[54] XIAOHUA S., YULIN Z. The implementation of dynamic hetero skedasticity convertible SVM model in financial time series. In: Proceedings of the 2014 IEEE Workshop on Advanced Research and Technology in Industry Applications (WARTIA), Ottawa, ON, Canada. IEEE, 2014, pp. 281-285, doi: 10.1109/wartia.2014.6976252.

[55] YACAMINI R. Power system harmonics: Part 3. Problems caused by distorted supplies. Power Engineering Journal. 1995, 9(2), pp. 233-238.

[56] YANG Y., WANG J., YANG Y. Improving SVM classifier with prior knowledge in micro calcification detection. In: Proceedings of the 2012 19th IEEE International Conference on Image Processing, Orlando, FL, USA. IEEE, 2012, pp. 2837-2840, doi: 10.1109/icip. 2012. 6467490.

[57] YANG Y., ZHANG C. Density Function Estimation Based on SVM: An Application in Estimating Liquidity Risk in Stock Market. In: Proceedings of the 2009 International Conference on Computational Intelligence and Software Engineering (CISE 2009), Wuhan, China. IEEE, 2009, pp. 1-5, doi: 10.1109/cise.2009.5362895.

[58] YEPEZ E.C., VIDALES H.M., PEREZ A.G., GARCIA J.M.L. Harmonic component estimation through DFSWT for active power filter applications. In: Proceedings of the IECON 2013 - 39th Annual Conference of the IEEE on Industrial Electronics Society, Vienna, Austria. IEEE, 2013, pp. 810-815, doi: 10.1109/iecon.2013.6699238.

[59] YING C., QINGSHENG L. New Research on Harmonic Detection Based Neural for Power System. 2009 Third International Symposium on Intelligent Information Technology Application (IITA 2009), Nanchang, China. IEEE, 2009, pp. 113-116, doi: 10.1109/iita.2009. 146. 


\section{Neural Network World 3/2016, 233-252}

[60] YU D., YUAN X., JIANXUN Z. Wavelet based harmonic parameter estimation in nonGaussian impulsive noise environments. In: Proceedings of the 2015 34th Chinese Control Conference (CCC), Hangzhou, China. IEEE, 2015, pp. 4512-4516, doi: 10.1109/chicc. 2015.7260338.

[61] YU J., YANG L. Analysis of harmonic and inter harmonic based on Hilbert-Huang Transform. In: Proceedings of the 2009 International Conference on Computational Intelligence and Software Engineering (CISE 2009), Wuhan, China. IEEE, 2009, pp. 1-4, doi: 10.1109/CISE. 2009.5365111.

[62] YUAN Q.B., SHENG T.Z., GAO Y., WEN H. An approach electrical harmonic analysis based on Nuttall window double-spectrum-line interpolation FFT. In: Proceedings of the CSEE, China. 2008, 28(25), pp. 153-158.

[63] ZHANG S., WANG Q., LIU R. Power system harmonic analysis based on improved HilbertHuang Transform. In: Proceedings of the 2009 9th International Conference on Electronic Measurement \& Instruments (ICEMI'09), Beijing, China. IEEE, 2009, pp. 343-347, doi: 10. 1109/ICEMI . 2009.5274060.

[64] ZHU Z., YUKUN S. Magnetic Bearing Rotor Displacement Estimation Using O-RLS-SVM In: Proceedings of the 2010 International Conference on Intelligent Computing and Intelligent Systems (ICIS), Xiamen, China. IEEE, 2010, pp. 727-731, doi: 10.1109/icicisys. 2010.5658485 . 